\title{
Effects of Potassium Chloride on the Reduction of
}

\section{Iron Oxides*}

\section{By Hiroshi NAKAGAWA** and Yöichi ONO**}

\section{Introduction}

Alkaline metal compounds enter a blast furnace accompanying the burden gangue and coke ash. Although their input is usually very low, they are circulated and consequently accumulated over a period of time in the blast furnace. The alkali compounds circulating in the blast furnace create serious problems to the smooth functioning of the furnace by causing the disintegration of ore and coke, the formation of scaffolds on the furnace wall, etc. ${ }^{1,2}$ ) A study of their effects on various blast furnace reactions is therefore very important.

One of the effects of alkali compounds is the acceleration of the reduction of iron oxides. Khalafalla and Weston, $\mathrm{Jr}^{3}{ }^{3)}$ found that alkaline and alkaline-earth metal oxides increased the reduction rate of wustite pellets by carbon monoxide. Itaya et $\left.a l .{ }^{4}\right)$ found in the stepwise reduction of hematite pellets by carbon monoxide that sodium chloride increased the rate of reduction step of $\mathrm{FeO} \rightarrow \mathrm{Fe}$ but it had no effect on the reduction steps of $\mathrm{Fe}_{2} \mathrm{O}_{3} \rightarrow$ $\mathrm{Fe}_{3} \mathrm{O}_{4}$ and $\mathrm{Fe}_{3} \mathrm{O}_{4} \rightarrow \mathrm{FeO}$.

In this paper, effects of potassium chloride on the rate of reduction of dense hematite, magnetite and wustite plates by carbon monoxide have been investigated in order to find a reduction step or steps on which the alkali compound has effects.

\section{Experimental Method}

Hematite, magnetite and wustite samples were prepared by oxidizing electrolytic iron plates $(25 \times$ $15 \times 0.1 \mathrm{~mm}$ ) according to the method shown in Table 1. The samples thus obtained were dense oxide plates, which were more suitable than porous pellets for examining the effects of $\mathrm{KCl}$ on the change of microstructure of the oxides during reduction.

Potassium chloride was added to an oxide sample by dipping the sample in a KGl-saturated aqueous solution and then drying it at $120^{\circ} \mathrm{C}$. The potassium chloride adsorbed on the oxide surface was gradually evaporated while the sample was heated to a reduction temperature in a nitrogen atmosphere. The $\mathrm{KGl}$ content at the start of reduction was less than 100 ppm.

Reduction experiments were carried out in a thermobalance under a flow of $2 \mathrm{~N} l / \mathrm{min}$ of a $\mathrm{CO}$ $\mathrm{CO}_{2}$ gas mixture at $900{ }^{\circ} \mathrm{C}$. The gas composition was $10 \% \mathrm{CO}-90 \% \mathrm{CO}_{2}$ for the reduction step of
$\mathrm{Fe}_{2} \mathrm{O}_{3} \rightarrow \mathrm{Fe}_{3} \mathrm{O}_{4}, 50 \% \mathrm{CO}-50 \% \mathrm{CO}_{2}$ for $\mathrm{Fe}_{3} \mathrm{O}_{4} \rightarrow \mathrm{FeO}$, and $90 \% \mathrm{CO}-10 \% \mathrm{CO}_{2}$ for $\mathrm{FeO} \rightarrow \mathrm{Fe}$ and $\mathrm{Fe}_{2} \mathrm{O}_{3} \rightarrow$ Fe.

The surface and cross section of samples were examined with a SEM before and after reduction.

\section{Results and Discussion}

\section{Reduction of Hematite Plates}

Figure 1 shows the reduction curves for the reduction of hematite plates with and without $\mathrm{KCl}$ addition by $90 \% \mathrm{CO}-10 \% \mathrm{CO}_{2}$ at $900{ }^{\circ} \mathrm{C}$. From this figure, the accelerating effect of potassium chloride on the continual reduction of hematite to iron is evident.

Figures 2 to 4 show the results of stepwise reduction of hematite plates with and without the addition of KCl. As it is apparent from these figures, potassium chloride accelerates the reduction rate of all the reduction steps: $\mathrm{Fe}_{2} \mathrm{O}_{3} \rightarrow \mathrm{Fe}_{3} \mathrm{O}_{4}, \mathrm{Fe}_{3} \mathrm{O}_{4} \rightarrow \mathrm{FeO}$, and $\mathrm{FeO} \rightarrow \mathrm{Fe}$.

Photograph 1 shows SEM micrographs of lightly polished cross section of magnetite, wustite, and iron produced by stepwise reduction of hematite plates.

Table 1. Preparation of oxide samples.

\begin{tabular}{l|l|rrc}
\hline \multirow{2}{*}{ Sample } & \multirow{2}{*}{ Material } & \multicolumn{3}{|c}{ Oxidizing condition } \\
\cline { 3 - 5 } & & $\begin{array}{c}\text { Temper- } \\
\text { ature }\left({ }^{\circ} \mathrm{C}\right)\end{array}$ & $\begin{array}{c}\text { Time } \\
(\mathrm{hr})\end{array}$ & Atmosphere \\
\hline $\mathrm{FeO}$ & Fe plate & 1250 & 8 & $\mathrm{CO}-\mathrm{CO}_{2}(1: 1)$ \\
$\mathrm{Fe}_{3} \mathrm{O}_{4}$ & Fe plate & 1000 & 5 & $\mathrm{CO}-\mathrm{CO}_{2}(1: 9)$ \\
$\mathrm{Fe}_{2} \mathrm{O}_{3}$ & $\mathrm{FeO}$ plate & 850 & 24 & air \\
\hline
\end{tabular}

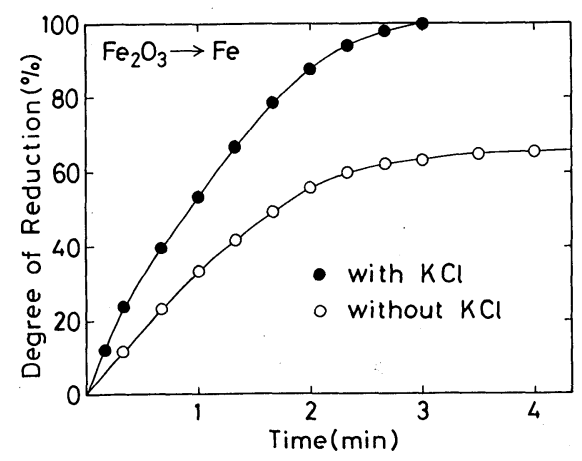

Fig. 1. Effect of $\mathrm{KCl}$ addition on the continual reduction of dense $\mathrm{Fe}_{2} \mathrm{O}_{3}$ plate to $\mathrm{Fe}$ by $90 \% \mathrm{CO}-10 \% \mathrm{CO}_{2}$ at $900{ }^{\circ} \mathrm{C}$.

\footnotetext{
* Presented to the 108th ISIJ Meeting, October 1984, S828, at Hiroshima University in Higashihiroshima. Manuscript received on March 4, 1985; accepted in the final form on May 10, 1985. (C) 1985 ISIJ

** Department of Iron and Steel Metallurgy, Faculty of Engineering, Kyushu University, Hakozaki, Higashi-ku, Fukuoka 812.
} 


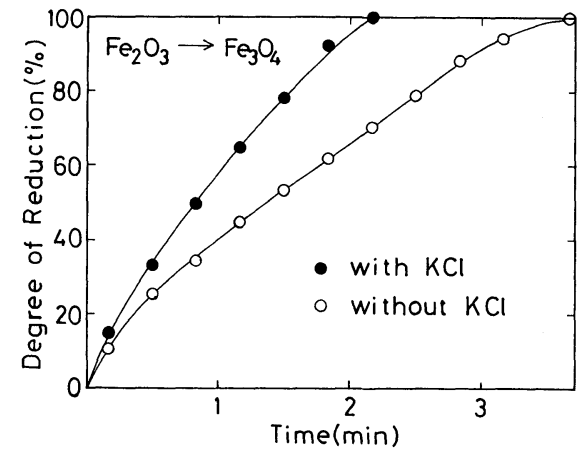

Fig. 2. Effect of $\mathrm{KCl}$ addition on the reduction step from $\mathrm{Fe}_{2} \mathrm{O}_{3}$ to $\mathrm{Fe}_{3} \mathrm{O}_{4}$ in the stepwise reduction of dense $\mathrm{Fe}_{2} \mathrm{O}_{3}$ plate.

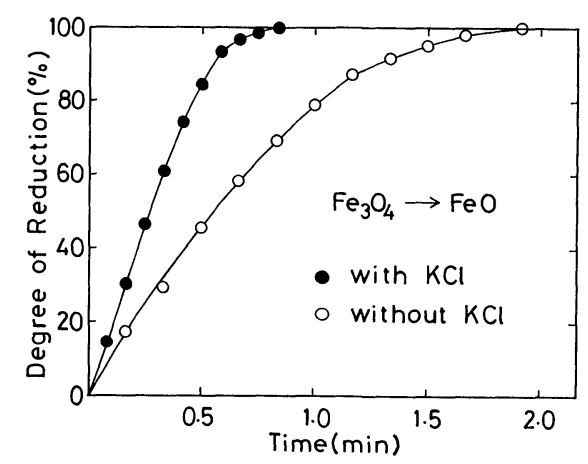

Fig. 3. Effect of $\mathrm{KCl}$ addition on the reduction step from $\mathrm{Fe}_{3} \mathrm{O}_{4}$ to $\mathrm{FeO}$ in the stepwise reduction of dense $\mathrm{Fe}_{2} \mathrm{O}_{3}$ plate.

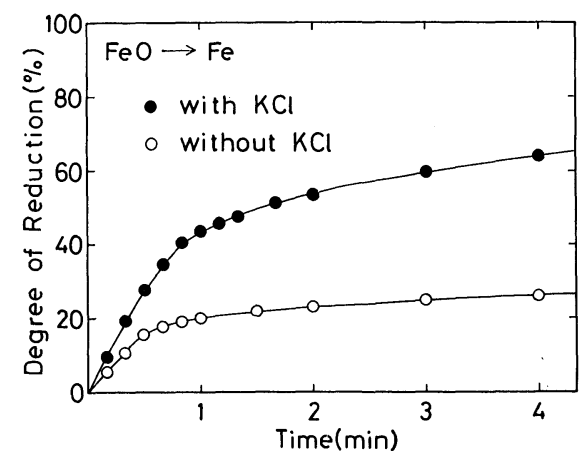

Fig. 4. Effect of $\mathrm{KCl}$ addition on the reduction step from $\mathrm{FeO}$ to $\mathrm{Fe}$ in the stepwise reduction of dense $\mathrm{Fe}_{2} \mathrm{O}_{3}$ plate.

Reduction proceeded from the right on the photographs to the left. Although hematite samples were dense, pores were formed during their reduction. In the magnetite reduced from the hematite sample without $\mathrm{KCl}$ addition, the pores were regularly extended from the surface of the sample inward. On the other hand, in the magnetite reduced from $\mathrm{KCl}$ added hematite, the pores were randomly distributed and had much larger contact area with reducing gas. Further reduction of magnetite to wustite and to iron increased the pore volume but did not change the pore morphology. The increase in the contact area with reducing gas by the addition of $\mathrm{KCl}$ seems to be responsible for the acceleration of reduction.
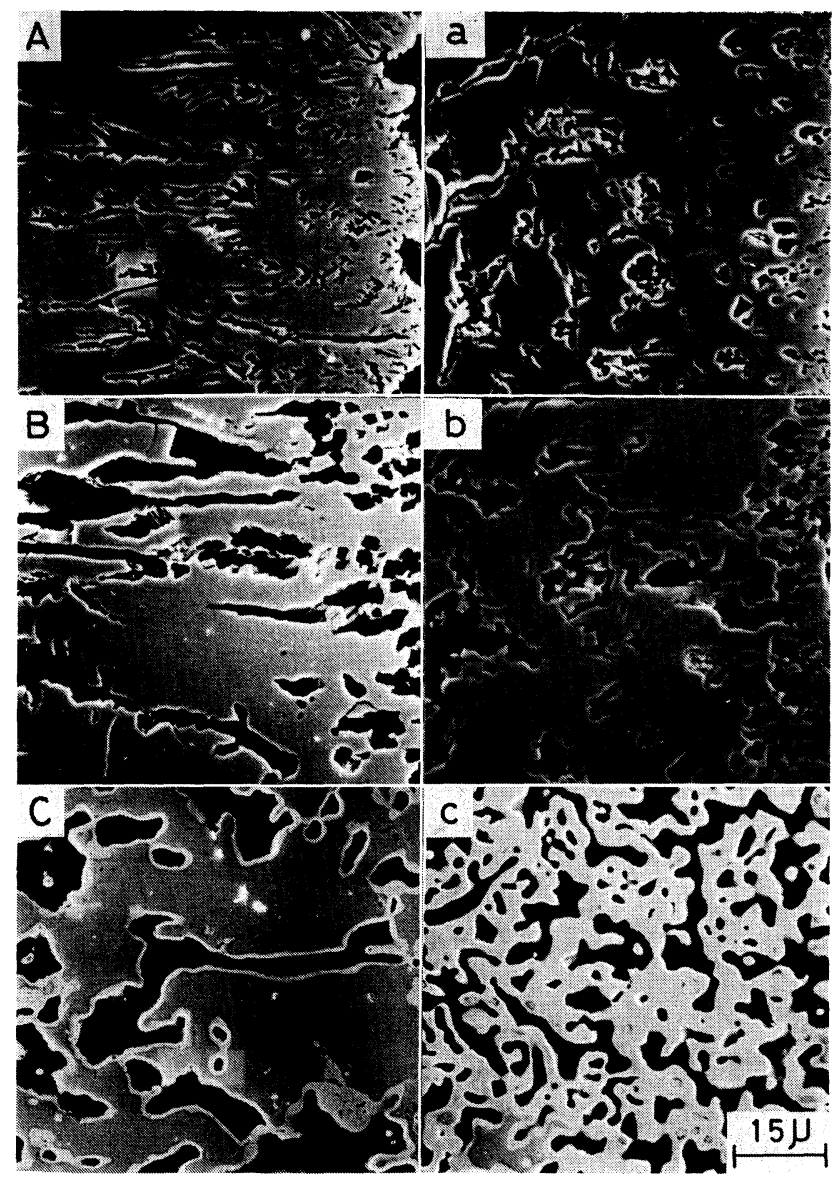

$\mathrm{A}, \mathrm{B}, \mathrm{C}$ : without $\mathrm{KCl}$ addition

$\mathrm{a}, \mathrm{b}, \mathrm{c}$ : with $\mathrm{KCl}$ addition

Photo. 1. SEM micrographs of cross sections of $\mathrm{Fe}_{3} \mathrm{O}_{4}$ (A, a), $\mathrm{FeO}(\mathrm{B}, \mathrm{b})$, and $\mathrm{Fe}(\mathrm{C}, \mathrm{c})$ produced by stepwise reduction of dense $\mathrm{Fe}_{2} \mathrm{O}_{3}$ plates.

\section{Reduction of Magnetite and Wustite Plates}

Reduction experiments were carried out by using dense magnetite and wustite plates, in order to investigate whether potassium chloride influenced directly the reduction of magnetite and wustite or indirectly through the difference in the pore structure of magnetite made during the reduction of hematite to magnetite.

Figure 5 shows the reduction curves for the reduction of dense magnetite plates to wustite. As is seen from this figure, potassium chloride added to the surface of magnetite also accelerates the reduction rate of magnetite.

Photograph 2 shows SEM micrographs of the surfaces of magnetite before reduction. As shown in Photo. 2(B), the grain boundary of magnetite was strongly eroded by $\mathrm{KCl}$, while the sample was heated to $900{ }^{\circ} \mathrm{C}$ in a nitrogen atmosphere.

Photograph 3 shows SEM micrographs of the surfaces of wustite produced by reduction of dense magnetite plates. Cubic crystals of wustite grew regularly on the surface of a magnetite sample without $\mathrm{KCl}$ addition, whereas the growth of wustite crystals was irregular on the surface of a magnetite sample with $\mathrm{KCl}$ addition. The potassium chloride adsorbed 


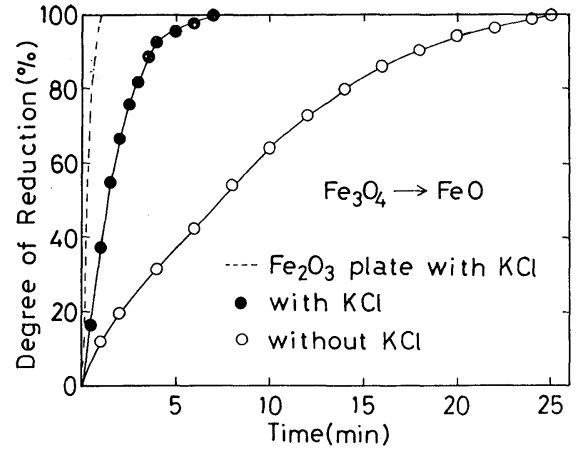

Fig. 5. Effect of $\mathrm{KCl}$ addition on the reduction of dense $\mathrm{Fe}_{3} \mathrm{O}_{4}$ plate to $\mathrm{FeO}$ by $50 \% \mathrm{CO}-50 \% \mathrm{CO}_{2}$ at $900{ }^{\circ} \mathrm{C}$. (The broken line refers to the reduction step from $\mathrm{Fe}_{3} \mathrm{O}_{4}$ to $\mathrm{FeO}$ in the stepwise reduction of $\mathrm{KCl}$ added dense $\mathrm{Fe}_{2} \mathrm{O}_{3}$ plate shown in Fig. 3.)

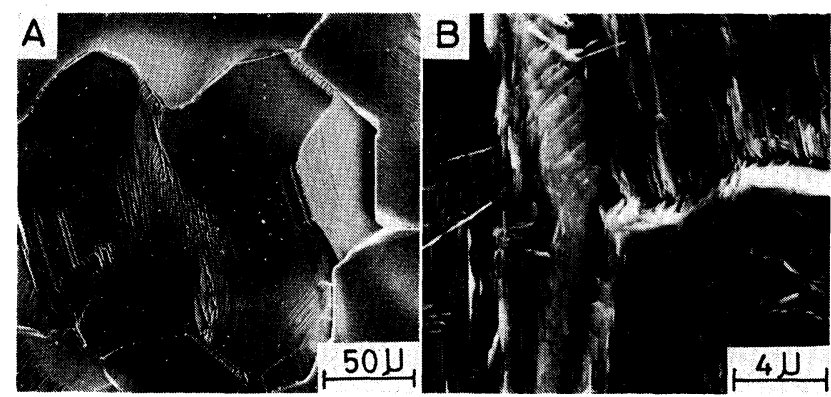

A: without $\mathrm{KCl}$ addition

$\mathrm{B}$ : with $\mathrm{KCl}$ addition

Photo. 2. SEM micrographs of surfaces of dense $\mathrm{Fe}_{3} \mathrm{O}_{4}$ plates before reduction.

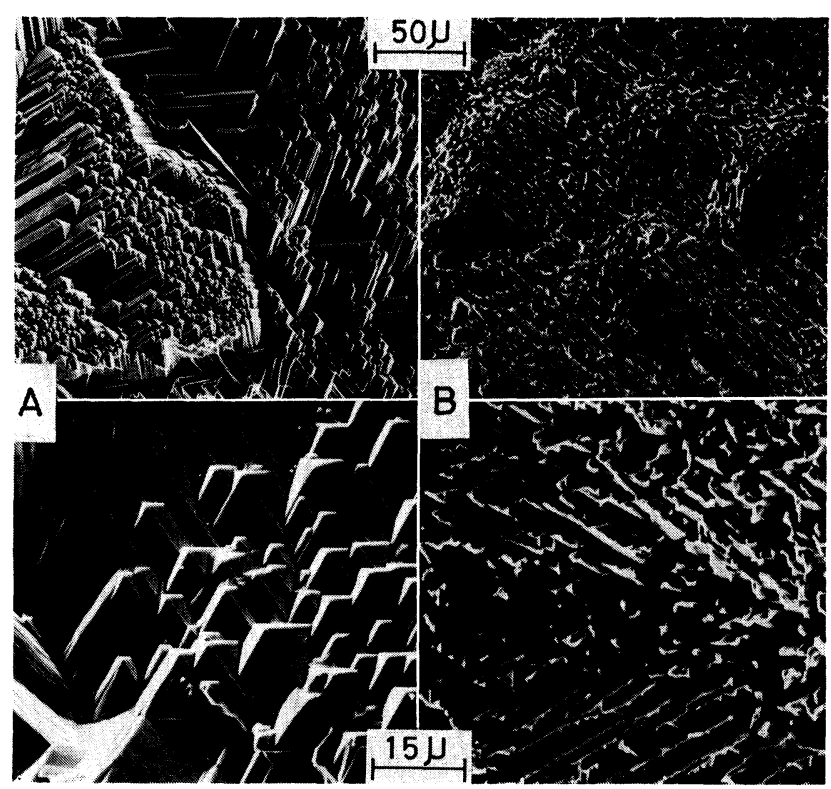

A: without $\mathrm{KCl}$ addition

$\mathrm{B}$ : with $\mathrm{KCl}$ addition

Photo. 3. SEM micrographs of $\mathrm{FeO}$ surfaces produced by reduction of dense $\mathrm{Fe}_{3} \mathrm{O}_{4}$ plates.

on the surface of magnetite probably affected the nucleation and growth of wustite phase and caused the irregular and distorted crystals to grow. The

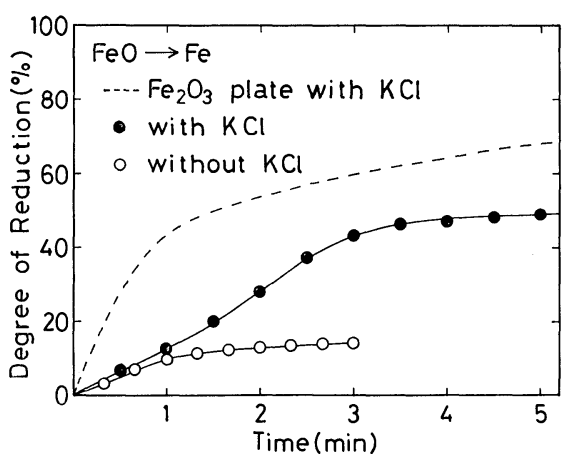

Fig. 6. Effect of $\mathrm{KCl}$ addition on the reduction of dense $\mathrm{FeO}$ plate to $\mathrm{Fe}$ by $90 \% \mathrm{CO}-10 \% \mathrm{CO}_{2}$ at $900{ }^{\circ} \mathrm{C}$. (The broken line refers to the reduction step from $\mathrm{FeO}$ to $\mathrm{Fe}$ in the stepwise reduction of $\mathrm{KCl}$-added dense $\mathrm{Fe}_{2} \mathrm{O}_{3}$ plate shown in Fig. 4.)

diffusion of $\mathrm{Fe}^{2+}$ ions and vacancies can be greatly facilitated in the distorted lattice, which may be responsible for the accelerating effect of $\mathrm{KCl}$ on magnetite reduction.

In Fig. 5, the reduction curve of porous magnetite reduced from dense hematite with $\mathrm{KCl}$ addition was also shown in a broken line. The difference in the reduction rate between dense hematite and dense magnetite samples for the same reduction step of $\mathrm{Fe}_{3} \mathrm{O}_{4} \rightarrow \mathrm{FeO}$ is due to the difference in the porosity of magnetite at the start of reduction.

Figure 6 shows the reduction curves for the reduction of dense wustite plates. Potassium chloride had also an accelerating effect on the reduction of wustite but the effect was smaller, especially at the beginning of reduction, than that on the reduction of porous wustite reduced from dense hematite sample, the reduction curve of the latter being shown in a broken line in Fig. 6. No significant difference in the microstructure of wustite samples before and after reduction with and without the addition of $\mathrm{KCl}$ was found and the effect of $\mathrm{KCl}$ could not be clarified in terms of morphology.

\section{Summary}

Effects of potassium chloride on the reduction of iron oxides were investigated by using dense hematite, magnetite, and wustite samples prepared by the oxidation of electrolytic iron plates.

The addition of small amount of $\mathrm{KCl}$ to the surfaces of oxide samples was found to greatly increase the reduction rate of all the reduction steps: $\mathrm{Fe}_{2} \mathrm{O}_{3}$ $\rightarrow \mathrm{Fe}_{3} \mathrm{O}_{4}, \mathrm{Fe}_{3} \mathrm{O}_{4} \rightarrow \mathrm{FeO}$, and $\mathrm{FeO} \rightarrow \mathrm{Fe}$.

Reduction of hematite with $\mathrm{KCl}$ addition produced very porous magnetite having larger contact area with reducing gas. In the reduction of magnetite with $\mathrm{KCl}$ addition, the grain boundary on the surface was strongly eroded and distorted wustite crystals were formed on the magnetite surface. These phenomena were considered to be responsible for the accelerating effects of $\mathrm{KCl}$ on the reduction of hematite and magnetite. However, the accelerating effect of $\mathrm{KCl}$ on wustite reduction could not be clarified in terms 
of morphology.

\section{REFERENCES}

1) K. P. Abraham and L. I. Staffansson: Scand. J. Metallurgy, 4 (1975), 193.
2) J. Davies, J. T. Moon and F. B. Traice: Ironmaking Steelmaking, 5 (1978), 151.

3) S. E. Khalafalla and P. L. Weston, Jr.: Trans. Met. Soc., AIME, 239 (1967), 1494.

4) H. Itaya, H.-W. Gudenau and K. S. Goto: Trans. ISIJ, 15 (1975), 429. 